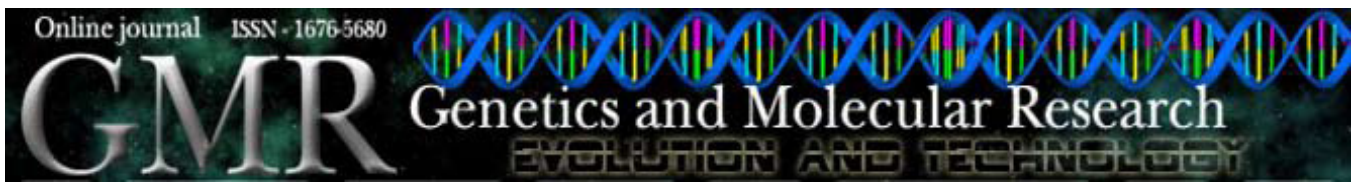

\title{
Comparison of different models to estimate genetic parameters for carcass traits in a commercial broiler line
}

\author{
J.L.B.M. Grosso ${ }^{1}$, J.C.C. Balieiro ${ }^{1}$, J.P. Eler ${ }^{1}$, J.B.S. Ferraz ${ }^{1}$, E.C. Mattos ${ }^{1}$ \\ and T. Michelan Filho ${ }^{2}$ \\ ${ }^{1}$ Departamento de Ciências Básicas, \\ Faculdade de Zootecnia e Engenharia de Alimentos, \\ Universidade de São Paulo, Pirassununga, SP, Brasil \\ ${ }^{2}$ Aviagen do Brasil Ltda., Rio Claro, SP, Brasil \\ Corresponding author: J.L.B.M. Grosso \\ E-mail: janelaragrosso@usp.br
}

Genet. Mol. Res. 9 (2): 908-918 (2010)

Received January 18, 2010

Accepted February 18, 2010

Published May 18, 2010

DOI 10.4238/vol9-2gmr773

\begin{abstract}
The effect of genetic and non-genetic factors for carcass, breast meat and leg weights, and yields of a commercial broiler line were investigated using the restricted maximum likelihood method, considering four different animal models, including or excluding maternal genetic effect with covariance between direct and maternal genetic effects, and maternal permanent environmental effect. The likelihood ratio test was used to determine the most adequate model for each trait. For carcass, breast, and leg weight, and for carcass and breast yield, maternal genetic and permanent environmental effects as well as the covariance between direct and maternal genetic effects were significant. The estimates of direct and maternal heritability were 0.17 and 0.04 for carcass weight, 0.26 and 0.06 for breast weight, 0.22 and 0.02 for leg weight, 0.32 and 0.02 for carcass yield, and 0.52 and 0.04 for breast yield, respectively. For leg yield, maternal permanent environmental effect was important, in addition to direct genetic effects. For that trait, direct heritability and maternal permanent environmental
\end{abstract}


variance as a proportion of the phenotypic variance were 0.43 and 0.02 , respectively. The results indicate that ignoring maternal effects in the models, even though they were of small magnitude ( 0.02 to 0.06 ), tended to overestimate direct genetic variance and heritability for all traits.

Key words: Animal model; Carcass yield; Heritability; Likelihood ratio test; Maternal effect

\section{INTRODUCTION}

In animal breeding, it is important to determine breeding value with the objective of classifying the best individuals that will be the parents in the next generation, and quantifying its contribution to the genetic gain. Therefore, it is indispensable that the genetic component is isolated from the other components, regarding different factors that affect the phenotypic value in each individual, through the proposal of more precise models to obtain more reliable genetic parameters. According to Pita and Albuquerque (2001), the accurate estimation of breeding values of individuals submitted to a breeding program depends, in most cases, on the effects considered in the statistical model used to evaluate the animals.

The breakdown of the phenotypic variance into genetic and environmental variance components is based on the principle that the phenotypic resemblance between parents provides information regarding the level of genetic difference between them. The additive component of the genetic variance is of particular interest because it is the primary determinant of the degree of resemblance between parent and progeny, and this governs the response rate of traits to selection (Lynch and Walsh, 1998). However, non-genetic variances are also important factors in determining the total variability of some repeated traits.

The maternal effect is defined, according to Hohenboken (1985), as any contribution, influence or impact of a dam on its progeny, excluding the effects of directly transmitted genes. The maternal effect in the progeny phenotype can be caused by genetic or environmental differences between mothers or by the combination of the genetic and environmental differences. This way, the maternal effect has genetic properties, such as heritability, repeatability, and genetic correlations with other traits of interest in animal production. It can be transitory but can also persist throughout life and be fulfilled through a great variety of biological mechanisms. Maternal effects in birds are different from those of mammals because any maternal effect on chicks, incubated artificially, must be the residual effect of dam reflected in egg characteristics at laying (Saatci et al., 2006). Willham (1980) emphasizes that knowledge of the type and relative importance of the genetic variation attributed to the maternal effect and, especially, to the type and magnitude of the genetic correlation between the direct and maternal additive effects of the traits is of high economic importance in the elaboration of breeding programs, where an evaluation of this effect is then necessary in each specific situation.

The primary goal of broiler breeding is to improve profitability of broiler meat production. Poultry production and processing technologies have become rapidly accessible and are being implemented on a worldwide basis, which will allow continued expansion and competitiveness in this meat sector (Aho, 2001). Therefore, the success of broiler meat production has been strongly related to the intense selection process carried out and the use of crossbreeding among breeds, which has resulted in a change in traditional concepts, producing specific lines 
with particular characteristics. As a result of this entire process, the focus for the selection of commercial broiler lines, considering mainly the male lines (Lesson and Summers, 2000), has been much more intense for the carcass traits, providing advances in terms of carcass and portion yield of the animals, as a consequence of a world trend of the largest consumption of chicken meat being in parts (Flemming et al., 1999), mainly breast meat (Pollock, 1997).

Besides the required high technology of production, it is also extremely necessary to the development of broiler breeding programs, the definition of the model to be applied to the data set to obtain unbiased estimates of genetic parameters. According to Henderson (1984), modeling is a very important aspect and it is very difficult in the application of linear models. In regards to poultry genetic evaluations, it is still unknown which random factors and which correlations must be included in the model. There are very few studies in the literature in this regard (Chambers, 1990; Chapuis et al., 1996; Koerhuis et al., 1997; Koerhuis and Thompson, 1997; Le Bihan-Duval et al., 1998; Pakdel et al., 2002), which makes its study much more important, trying to define the more adequate model in the unbiased estimates of the genetic parameters.

Genetic analyses of traits economically important in poultry have been used extensively in monitoring the genetic variability of each line, where the estimates of the genetic parameters are indispensable in establishing the selection programs. According to Falconer and Mackay (1996), with the estimation of the heritability coefficient it is possible to determine how much of the total variability connected to the expression of a trait corresponds to the genetic additive variation, which allows the establishment of more efficient selection programs. The estimate of genetic parameters in commercial broiler lines is a required condition in defining, guiding and evaluating the efficiency of the selection used in generations that make up this line and also in the adequacies of the selection for the requirements in the current production, industrial and consumption market.

Thus, the objective of the current study was to determine the importance of including the maternal additive genetic and permanent environmental effects in the animal genetic evaluation model to estimate genetic parameters for carcass traits in a commercial broiler line.

\section{MATERIAL AND METHODS}

\section{Data}

The information utilized came from siblings of an elite population of a commercial breeding program. These individuals are part of a program designated sib testing whose purpose is to evaluate carcass traits, helping to choose the best animals during the selection program of the elite population. The chicks were raised with vaccination programs and nutritional management as recommended by Agroceres Ross (2004). At 6 weeks, from November 2002 to December 2006, each flock of chickens was transported to the Experimental Processing Plant of the University of São Paulo, Pirassununga, SP, Brazil (21 $58^{\prime}$ 'S; $\left.47^{\circ} 26^{\prime} \mathrm{W}\right)$. The chickens were on feed and water withdrawal for a minimum period of $10 \mathrm{~h}$ before slaughter. After slaughter, the carcasses were stored in a cold room at $0^{\circ} \mathrm{C}$ for $24 \mathrm{~h}$, and then processed into portions and deboned.

The information collected from the individuals included: carcass weight $(\mathrm{CW})$, corresponding to the warm carcass weight, eviscerated, without neck, feet, abdominal fat, and 
internal organs; breast meat weight (BRW), corresponding to the boneless and skinless breast weight, recorded after the carcass was refrigerated, and leg weight (LW), corresponding to the thigh plus drumstick weight with skin and bones. The relative weights of carcass (CY), breast meat (BRY) and leg (LY) were calculated as the ratio between the absolute weight of each trait and the body weight (BW) at 6 weeks before slaughter. Approximately, 24,000 individuals were submitted for the collection of data for the carcass traits.

\section{Statistical analyses}

Data were processed at the Animal Breeding and Biotechnology Group, Department of Basic Sciences of the College of Animal Science and Food Engineering, University of São Paulo, Pirassununga, SP, Brazil. The extreme values were identified by the UNIVARIATE procedure of the SAS software (SAS Institute, 2004) and eliminated from the data set. The descriptive statistics obtained using the MEANS procedure of the SAS software (SAS Institute, 2004) are presented in Table 1.

\begin{tabular}{|c|c|c|c|c|c|c|}
\hline Trait & $\mathrm{N}$ & Mean & SD & CV (\%) & Min & Max \\
\hline$\overline{\mathrm{CW}}$ & 24,001 & $1,934.22$ & 284.99 & 14.73 & 798.00 & $2,882.00$ \\
\hline BRW & 23,529 & 534.32 & 94.51 & 17.69 & 199.00 & 902.00 \\
\hline LW & 23,515 & 671.11 & 113.26 & 16.88 & 260.00 & $1,028.00$ \\
\hline CY & 24,001 & 70.56 & 1.85 & 2.62 & 62.23 & 78.62 \\
\hline BRY & 23,529 & 19.52 & 1.87 & 9.58 & 12.49 & 27.51 \\
\hline LY & 23,515 & 24.47 & 1.44 & 5.87 & 17.47 & 31.80 \\
\hline
\end{tabular}

The pedigree contained 132,442 animals, and the estimates of the (co)variance components and the genetic parameters were obtained by the restricted maximum likelihood method, applied to animal models. The analyses were done using the MTDFREML software (Boldman et al., 1995), which instead of maximizing the natural logarithm of the likelihood function $(\log \mathrm{L})$, adopts the procedure of minimizing the $-2 \log \mathrm{L}$. The minimum point of -2 $\log \mathrm{L}$ was evaluated using the simplex method, defining the convergent criteria as the value of $10^{-9}$ with two consecutive re-starts without alteration of $-2 \log \mathrm{L}$ in the sixth decimal digit.

The analysis models included the fixed effects of the contemporary group, defined by hatch week (104 levels), mating group (50 levels), and sex of the animals (two levels). The mating groups are the flocks from which the parents of each individual originated, representing the total environmental condition in which these flocks were submitted and that influenced progeny performance. The importance of these effects was determined by the GLM procedure of the SAS software (SAS Institute, 2004), which was significant $(\mathrm{P}<0.0001)$ for the traits studied.

A series of 24 univariate analyses with four different animal models were developed according to inclusion or exclusion the maternal additive genetic effect with the covariance between direct and maternal additive genetic effects, and the maternal permanent environmental effect, in addition to the direct additive genetic effect. This way, the following models were obtained and can be described in matrix notation as: 


$$
\begin{gathered}
y=X b+Z_{1} a+e \\
y=X b+Z_{1} a+Z_{2} m+e ; \\
y=X b+Z_{1} a+W c+e \\
y=X b+Z_{1} a+Z_{2} m+W c+e
\end{gathered}
$$

where: $y$ is the vector of observations; $b$, the vector of fixed effects; $a$, the vector of random direct additive genetic effect; $\mathrm{m}$, the vector of random maternal additive genetic effect; $\mathrm{c}$, the vector of random maternal permanent environmental effect; e, the vector of random residual effect, and $\mathrm{X}, \mathrm{Z}_{1}, \mathrm{Z}_{2}$, and $\mathrm{W}$, the incidence matrices relating the observations to the fixed effects, random effects, direct and maternal additive genetic, and maternal permanent environmental, respectively.

The assumptions for the models were: $\mathrm{E}[\mathrm{y}]=\mathrm{Xb} ; \mathrm{E}[\mathrm{a}]=0 ; \mathrm{E}[\mathrm{m}]=0 ; \mathrm{E}[\mathrm{c}]=0 ; \mathrm{E}[\mathrm{e}]=0$, and

$$
\mathrm{V}\left[\begin{array}{c}
a \\
m \\
c \\
e
\end{array}\right]=\left[\begin{array}{cccc}
\mathrm{A} \sigma_{a}^{2} & \mathrm{~A} \sigma_{a, m} & 0 & 0 \\
\mathrm{~A} \sigma_{a, m} & \mathrm{~A} \sigma_{m}^{2} & 0 & 0 \\
0 & 0 & \mathrm{I} \sigma_{c}^{2} & 0 \\
0 & 0 & 0 & \mathrm{I} \sigma_{\varepsilon}^{2}
\end{array}\right]
$$

where: A is the relationship matrix; I, the identity matrix; $\sigma_{a}^{2}$, the direct additive genetic variance; $\sigma_{m}^{2}$, the maternal additive genetic variance; $\sigma_{a, m}$, the covariance between the direct and maternal additive genetic effects; $\sigma_{c}^{2}$, the variance due to the maternal permanent environmental effect, and $\sigma_{e}^{2}$, the variance due to the residual effect. The covariances between the genetic and environmental effects (permanent and residual) as well as between the environmental effects of different animals were assumed to be zero.

The likelihood ratio test (LRT) was used to see if the models differ statistically from one another, caused by the addition of a parameter to the model. This test is based on the chisquare distribution with $k$ degrees of freedom, where $k$ is equal to the number of additional parameters in the more complex model (Dobson, 2002). This way, LRT can be described as

$$
\chi_{k}^{2}=2 \log \mathrm{L}(\mathrm{F})-2 \log \mathrm{L}(\mathrm{R}),
$$

where L (F) is the likelihood of the full model and L (R), the likelihood of the residual model.

\section{RESULTS AND DISCUSSION}

\section{Maternal effects}

Table 2 shows the reduction in the value of $-2 \log \mathrm{L}$ and the significance of this reduction, resulting from the use of different models, for the analysis of each one of the carcass traits.

As can be seen in Table 2, for the majority of the traits analyzed there was a significant reduction in value of $-2 \log \mathrm{L}$ when the random effects maternal additive genetic with covariance between direct and maternal additive genetic effects (model 2) or maternal permanent environmental (model 3) or all (model 4) were included in the analysis model, in relation to 


\begin{tabular}{|c|c|c|c|c|c|}
\hline \multirow[t]{2}{*}{ Trait } & \multicolumn{5}{|c|}{ Reduction in value of $-2 \log \mathrm{L}$} \\
\hline & Model 2 - Model 1 & Model 3 - Model 1 & Model 4 - Model 1 & Model 4 - Model 2 & Model 4 - Model 3 \\
\hline $\mathrm{CW}$ & $84.635^{* *}$ & $183.173^{* *}$ & $231.622 * *$ & $146.987 * *$ & $48.449 * *$ \\
\hline BRW & $91.641 * *$ & $180.790 * *$ & $245.818^{* *}$ & $154.177 * *$ & $65.026 * *$ \\
\hline LW & $32.226^{* *}$ & $104.912 * *$ & $122.297 * *$ & $90.071 * *$ & $17.385^{* *}$ \\
\hline $\mathrm{CY}$ & $12.307 * *$ & $14.381 * *$ & $23.157^{* *}$ & $10.851 * *$ & $8.776^{*}$ \\
\hline BRY & $22.553^{* *}$ & $43.725^{* *}$ & $61.176^{* *}$ & $38.624 * *$ & $17.452 * *$ \\
\hline LY & $3.120^{\mathrm{ns}}$ & $5.068^{*}$ & $8.104 *$ & $4.984 *$ & $3.036^{\mathrm{ns}}$ \\
\hline
\end{tabular}

$\mathrm{L}=$ likelihood function. * $(\mathrm{P}<0.05) ; * *(\mathrm{P}<0.01) ; \mathrm{ns}=$ not significant.

the initial (model 1), which considered as random only the direct additive genetic effect of the animals. The significance of these effects indicates that they respond to an important part of the existing variation in the population for the traits considered. Therefore, it is expected that the inclusion of these effects in the genetic analysis model will lead to a more accurate prediction of the breeding value of the individuals under evaluation.

For CW, BRW, LW, CY, and BRY, the presence of both maternal genetic and permanent environmental effects as well as covariance between direct and maternal effects in the model resulted in a significant decrease in value of $-2 \log \mathrm{L}$ over the use of models 2 and $3(\mathrm{P}<$ 0.01). Therefore, model 4 is suggested as an adequate model for these traits. Model 3 was significantly better than the base model for LY but it was not different from the full model (model 4). This suggests that the maternal genetic effect had no additional effect when the permanent environmental effect was fitted for this trait. This agrees with Meyer (1992) who suggests that the inclusion of one of the maternal effects in the model can be enough to adjust the variation occurring in both effects (maternal additive genetic and permanent environmental).

In birds, the maternal environmental affects bird growth in two stages: preoviposition and postoviposition maternal effects. The postoviposition effect can be further divided into two components - prehatch (incubation) and posthatch. However, this maternal effect is not considered important in this case because chicks, incubated artificially, are raised independent of the dams. The preoviposition maternal effects include egg size, egg weight, egg (shell) quality, and yolk composition (Aggrey and Cheng, 1993). Koerhuis et al. (1997) reported that $1 \mathrm{~g}$ difference in egg weight is reflected in about $10 \mathrm{~g}$ difference in juvenile broiler BW. Many studies have shown a positive (phenotypic) effect of egg weight on juvenile broiler BW (Chambers, 1990). Koerhuis and McKay (1996) estimated a genetic correlation of 0.63 between juvenile broiler BW and egg weight. The genetic correlation estimates between BW and carcass traits (CW, BRW, and LW) have been reported in the literature and found to be 0.89 (Zerehdaran et al., 2004) to 0.97 (Gaya et al., 2006) for BW and CW, 0.43 (Gaya et al., 2006) to 0.77 (Le Bihan-Duval et al., 1998) for BW and BRW, and 0.84 to 0.93 (Gaya et al., 2006) for BW and LW.

The formation of the egg is a long process, since the maturation of the yolk until egg laying requires 24 to $26 \mathrm{~h}$, of which $20 \mathrm{~h}$ are for eggshell formation (Reece, 2006), which represents about $10 \%$ of egg weight (Etches, 1995). During the shell calcification process, $70 \%$ of the calcium comes from food and 30\% from medullary bone, and this is always in a dynamic state, being mobilized and deposited continuously. When there is a deficiency of dietary calcium, medullary bone calcium cannot meet the requirements for good eggshell formation, which results in increased porosity and loss of egg (shell) quality. These characteristics can result in differences between the eggs laid in the morning and in the afternoon (Harms, 1991), 
and possibly it may be suggested as a permanent effect during the production life of the dam.

Meyer (1992) addressed the difficulty of statistically separating the direct and maternal components of variance. According to Koerhuis and Thompson (1997), poultry data may be suitable for the estimation of maternal genetic variances owing to their size and structure with many offspring per dam and often many recorded generations available. Some data structure aspects, in this study, are presented in Table 3.

Table 3. Some structural aspects of the data for absolute weights of carcass (CW), breast meat (BRW) and leg (LW), and relative weights of carcass (CY), breast meat (BRY) and leg (LY).

\begin{tabular}{lccccc}
\hline Trait & Animals & Sires & Dams & Offspring per sire & Offspring per dam \\
\hline CW & 24,001 & 608 & 4,536 & 37.76 & 4.98 \\
BRW & 23,529 & 608 & 4,519 & 36.99 & 4.89 \\
LW & 23,515 & 608 & 4,519 & 36.97 & 4.89 \\
CY & 24,001 & 608 & 4,536 & 37.76 & 4.98 \\
BRY & 23,529 & 608 & 4,519 & 36.99 & 4.89 \\
LY & 23,515 & 608 & 4,519 & 36.97 & 4.89 \\
\hline
\end{tabular}

The problem in using the models that do not appropriately consider the effects that contribute efficiently to the composition of the phenotypic variation, model 1 in this case, is that they focus mainly on the reduction in the efficiency of the selection process due to the lack of precision in determining relationships between genotypes and phenotypes (Lynch and Walsh, 1998).

\section{Heritability estimates}

The estimates of the heritability coefficients for the direct and maternal additive genetic effects and the variances of the maternal permanent environmental in relation to the total phenotypic variance, for the corresponding models, are presented in Table 4 for the absolute weights and in Table 5 for the relative weights of the carcass traits analyzed.

Table 4. Components of (co)variances and estimates of genetic parameters with respective standard errors (in parentheses) for absolute weights of carcass (CW), breast meat (BRW) and leg (LW), utilizing the four models proposed.

\begin{tabular}{|c|c|c|c|c|c|c|c|c|c|c|c|}
\hline \multirow[t]{2}{*}{ Trait } & \multirow[t]{2}{*}{ Model } & \multicolumn{5}{|c|}{ Variance components $^{\mathrm{a}}$} & \multicolumn{5}{|c|}{ Genetic parameters $^{\mathrm{b}}$} \\
\hline & & $\hat{\sigma}_{a}^{2}$ & $\hat{\sigma}_{a, m}$ & $\hat{\sigma}_{m}^{2}$ & $\hat{\sigma}_{c}^{2}$ & $\hat{\sigma}_{e}^{2}$ & $\hat{h}_{a}^{2}$ & $\hat{r}_{a, m}$ & $\hat{h}_{m}^{2}$ & $\hat{c}^{2}$ & $\hat{e}^{2}$ \\
\hline \multirow[t]{4}{*}{$\overline{\mathrm{CW}}$} & 1 & $6,623.6556$ & - & - & - & $19,464.5292$ & $0.26(0.02)$ & - & - & - & $0.74(0.02)$ \\
\hline & 2 & $5,091.7689$ & $-1,870.7743$ & $2,568.6664$ & - & $19,905.2152$ & $0.20(0.02)$ & $-0.52(0.08)$ & $0.10(0.02)$ & - & $0.77(0.02)$ \\
\hline & 3 & $2,594.9573$ & - & - & $2,113.5813$ & $20,585.0916$ & $0.10(0.01)$ & - & - & $0.08(0.01)$ & $0.81(0.01)$ \\
\hline & 4 & $4,351.1482$ & $-1,786.9321$ & 996.4452 & $2,093.3327$ & $19,711.5372$ & $0.17(0.02)$ & $-0.86(0.06)$ & $0.04(0.01)$ & $0.08(0.01)$ & $0.78(0.02)$ \\
\hline \multirow[t]{4}{*}{ BRW } & 1 & $1,307.2042$ & - & - & - & $1,974.2730$ & $0.40(0.02)$ & - & - & - & $0.60(0.02)$ \\
\hline & 2 & 919.0366 & -326.8760 & 456.2944 & - & $2,141.7349$ & $0.29(0.03)$ & $-0.51(0.08)$ & $0.14(0.02)$ & - & $0.67(0.02)$ \\
\hline & 3 & 493.3894 & - & - & 309.0858 & $2,298.7694$ & $0.16(0.02)$ & - & - & $0.10(0.01)$ & $0.74(0.01)$ \\
\hline & 4 & 797.0170 & -342.5057 & 188.6011 & 323.7846 & $2,146.5300$ & $0.26(0.03)$ & $-0.88(0.05)$ & $0.06(0.01)$ & $0.10(0.01)$ & $0.69(0.02)$ \\
\hline \multirow[t]{4}{*}{ LW } & 1 & $1,147.8290$ & - & - & - & $2,598.6437$ & $0.31(0.02)$ & - & - & - & $0.69(0.02)$ \\
\hline & 2 & 955.0767 & -96.6117 & 181.9596 & - & $2,676.8085$ & $0.26(0.02)$ & $-0.23(0.11)$ & $0.05(0.01)$ & - & $0.72(0.02)$ \\
\hline & 3 & 653.1374 & - & - & 239.6751 & $2,765.1287$ & $0.18(0.02)$ & - & - & $0.07(0.01)$ & $0.76(0.01)$ \\
\hline & 4 & 823.3359 & -163.7607 & 79.5636 & 247.8945 & $2,680.0012$ & $0.22(0.02)$ & $-0.64(0.10)$ & $0.02(0.01)$ & $0.07(0.01)$ & $0.73(0.02)$ \\
\hline
\end{tabular}

${ }^{\mathrm{a}} \hat{\sigma}_{a}^{2}=$ direct additive genetic variance; $\hat{\sigma}_{m}^{2}=$ maternal additive genetic variance; $\hat{\sigma}_{a, m}=$ covariance between the direct and maternal additive genetic effects; $\hat{\sigma}_{c}^{2}=$ variation due to maternal permanent environmental effects; $\hat{\sigma}_{e}^{2}=$ variation due to residual effects. ${ }^{b} \hat{h}_{a}^{2}=$ heritability coefficient for the direct additive genetic effect; $\hat{h}_{m}^{2}=$ heritability coefficient for the maternal additive genetic effect; $\hat{r}_{a, m}=$ correlation coefficient between direct and maternal additive genetic effects; $\hat{c}^{2}=$ maternal permanent environment effect given as a reason for variation in phenotype; $\hat{e}^{2}=$ residual effect given as a reason for variation in phenotype. 


\begin{tabular}{|c|c|c|c|c|c|c|c|c|c|c|c|}
\hline \multirow[t]{2}{*}{ Trait } & \multirow[t]{2}{*}{ Model } & \multicolumn{5}{|c|}{ Variance components ${ }^{\mathrm{a}}$} & \multicolumn{5}{|c|}{ Genetic parameters $^{\mathrm{b}}$} \\
\hline & & $\hat{\sigma}_{a}^{2}$ & $\hat{\sigma}_{a, m}$ & $\hat{\sigma}_{m}^{2}$ & $\hat{\sigma}_{c}^{2}$ & $\hat{\sigma}_{e}^{2}$ & $\hat{h}_{a}^{2}$ & $\hat{r}_{a, m}$ & $\hat{h}_{m}^{2}$ & $\hat{c}^{2}$ & $\hat{e}^{2}$ \\
\hline \multirow[t]{4}{*}{$\overline{\mathrm{CY}}$} & 1 & 0.6868 & - & - & - & 1.2467 & $0.36(0.02)$ & - & - & - & $0.64(0.02)$ \\
\hline & 2 & 0.6443 & -0.0404 & 0.0541 & - & 1.2641 & $0.34(0.03)$ & $-0.22(0.11)$ & $0.03(0.01)$ & - & $0.66(0.02)$ \\
\hline & 3 & 0.5575 & - & - & 0.0491 & 1.2983 & $0.29(0.02)$ & - & - & $0.03(0.01)$ & $0.68(0.02)$ \\
\hline & 4 & 0.6116 & -0.0639 & 0.0354 & 0.0524 & 1.2714 & $0.32(0.03)$ & $-0.43(0.13)$ & $0.02(0.01)$ & $0.03(0.01)$ & $0.67(0.02)$ \\
\hline \multirow[t]{4}{*}{ BRY } & 1 & 1.0629 & - & - & - & 0.6157 & $0.63(0.02)$ & - & - & - & $0.37(0.02)$ \\
\hline & 2 & 0.9098 & -0.0591 & 0.1017 & - & 0.6880 & $0.55(0.04)$ & $-0.19(0.09)$ & $0.06(0.02)$ & - & $0.42(0.03)$ \\
\hline & 3 & 0.7341 & - & - & 0.0918 & 0.7663 & $0.46(0.03)$ & - & - & $0.06(0.01)$ & $0.48(0.02)$ \\
\hline & 4 & 0.8341 & -0.1207 & 0.0573 & 0.1075 & 0.7163 & $0.52(0.04)$ & $-0.55(0.10)$ & $0.04(0.01)$ & $0.07(0.01)$ & $0.45(0.03)$ \\
\hline \multirow[t]{4}{*}{ LY } & 1 & 0.4726 & - & - & - & 0.5299 & $0.47(0.02)$ & - & - & - & $0.53(0.02)$ \\
\hline & 2 & 0.4616 & -0.0093 & 0.0123 & - & 0.5347 & $0.46(0.03)$ & $-0.12(0.16)$ & $0.01(0.01)$ & - & $0.54(0.03)$ \\
\hline & 3 & 0.4237 & - & - & 0.0161 & 0.5510 & $0.43(0.03)$ & - & - & $0.02(0.01)$ & $0.56(0.02)$ \\
\hline & 4 & 0.4426 & -0.0213 & 0.0099 & 0.0187 & 0.5415 & $0.45(0.03)$ & $-0.32(0.18)$ & $0.01(0.01)$ & $0.02(0.01)$ & $0.55(0.02)$ \\
\hline
\end{tabular}

${ }^{\mathrm{a}} \hat{\sigma}_{a}^{2}=$ direct additive genetic variance; $\hat{\sigma}_{m}^{2}=$ maternal additive genetic variance; $\hat{\sigma}_{a, m}=$ covariance between the direct and maternal additive genetic effects; $\hat{\sigma}_{c}^{2}=$ variation due to maternal permanent environmental effects; $\hat{\sigma}_{e}^{2}=$ variation due to residual effects. ${ }^{.} \hat{h}_{a}^{2}=$ heritability coefficient for the direct additive genetic effect; $\hat{h}_{m}^{2}=$ heritability coefficient for the maternal additive genetic effect; $\hat{r}_{a, m}=$ correlation coefficient between direct and maternal additive genetic effects; $\hat{c}^{2}=$ maternal permanent environment effect given as a reason for variation in phenotype; $\hat{e}^{2}=$ residual effect given as a reason for variation in phenotype.

The direct heritability estimates were moderate for CW, BRW, LW, CY, and LY, and high for BRY, suggesting that the traits analyzed can be selected and that significant results for the selection can be obtained. These estimates were lower than those obtained by Argentão et al. (2002) for CW (0.34), BRW (0.45) and LW (0.34), Zerehdaran et al. (2004) for CW (0.33), BRW (0.47), CY (0.41) and BRY (0.73), and Gaya et al. (2006) for CW (0.24), BRW (0.33) and LW (0.33), all working with an animal model including as random effects direct additive genetic and residual. Le Bihan-Duval et al. (1998) found higher direct heritability for BRW in males (0.48) and females (0.58), and BRY in males (0.64) and females (0.66), using an animal model including direct genetic and common environmental effects.

Direct heritability coefficients for CY and BRY were similar to the ones observed by Gaya et al. (2005) who reported values of 0.30 and 0.51 , respectively. However, these authors, using an animal model including as random effects direct additive genetic and residual, found an estimate of direct heritability for LY of 0.35 , which was lower than that obtained in this study (Table 5).

Clément et al. (2001) demonstrated that if maternal genetic effects exist but they are not considered in the model, the direct heritability coefficient is overestimated, which can lead to wrong conclusions as all the variances found, except error, will be attributed to the direct additive genetic effect. Sometimes, this results in a direct heritability coefficient that is more than twice the true direct heritability (Clément et al., 2001). In the current study, large increases in the direct heritability were found for traits with a significant maternal genetic effect when this factor was not included in the model (model 1). Pakdel et al. (2002), working with ascites-related traits, also reported large increases in the direct heritability coefficients for these traits when the random maternal additive genetic factor was significant and taken from the analysis model. 


\section{Genetic correlation between direct and maternal effects}

The genetic correlations between the direct and maternal additive genetic effects $\left(r_{a, m}\right)$ to the traits analyzed were negative, although they differed in magnitude $(-0.86$, $-0.88,-0.64,-0.43$, and -0.55 , respectively for CW, BRW, LW, CY, and BRY). Koerhuis and Thompson (1997) also obtained large negative estimates of $r_{a, m}$ for juvenile broiler BW (-0.54), which was somewhat surprising since these authors expected a positive genetic correlation between juvenile broiler BW and egg weight (Koerhuis and McKay, 1996). According to the same authors, the genetic variance of maternal origin could, for the greater part, relate to egg (shell) quality rather than egg size, which could explain the negative sign of $r_{a, m}$. The antagonism between the direct and maternal additive effects was also observed by other authors for growth traits in Creole and Venda chickens (PradoGonzález et al., 2003; Norris and Ngambi, 2006).

Some authors have suggested that negative estimates and of medium and high magnitude for $r_{a, m}$ can be related to the size of the data set, its structure, and the magnitude of the direct and maternal additive genetic effects. According to Gerstmayr (1992), the reliability of the estimates of $r_{a, m}$ is strongly influenced due to the proportion between the components of direct and maternal additive genetic variance, and becomes smaller in populations where the maternal additive genetic effect is four times smaller than the direct additive genetic effect. In this study, the maternal additive genetic effect was, on average, 10 times smaller than the direct additive genetic effect, and therefore, the estimates of $r_{a, m}$ obtained here cannot be reliable.

Benyshek et al. (1988), in studies with three cattle data sets under simulated selection with true values of negative, null, and positive $r_{a, m}$, showed that the prediction accuracy of the direct additive genetic value was not affected by the $r_{a, m}$ used in the analyses, which did not happen for the prediction accuracy of the maternal additive genetic value when negative $r_{a, m}$ was used to analyze the simulated set with positive and vice-versa $r_{a, m}$. The authors concluded that the utilization of null $r_{a, m}$ when estimates of its true value are not available allows the accurate determination of direct and maternal additive genetic values. In poultry, there are few studies that discuss the estimates of $r_{a, m}$ for economically important traits. However, considering the difficulties in obtaining reliable estimates for $r_{a, m}$, assuming it as being null may be the best procedure for the genetic evaluation of traits in which the maternal additive genetic effect is important but of small magnitude.

Explanations of extreme estimates have also focused on the existence of environmental covariances between records of dam and offspring, and on the fixed effect structure used in statistical models for data analyses (Robinson, 1996; Koerhuis and Thompson, 1997; Meyer, 1997). However, according to Bijma (2006), accounting for environmental dam-offspring covariances will not always prevent extreme estimates for genetic correlation. The observation that genetic and phenotypic correlations are usually very similar (Lynch and Walsh, 1998) indicates that estimating direct-maternal genetic correlations while assuming zero environmental correlations represents a strong a priori assumption. Bijma (2006) suggested that before assuming that environmental correlations are zero, it is important to empirically validate this assumption. According to the same author, depending on the data structure, analyses of maternal effects while accounting for environmental dam-offspring covariances may not be feasible within standard software. In this study, the software used for the analyses did not permit us to fit the residual variance structure required for maternal effects. 


\section{CONCLUSION}

The present study showed that carcass traits were significantly influenced by maternal effects in this population of broilers. The results suggest that models considering maternal additive genetic and permanent environmental effect as well as the covariance between direct and maternal additive genetic effects, fitted better for CW, BRW, LW, CY, and BRY. For LY, maternal permanent environmental effect was important, in addition to direct additive genetic effect. Therefore, these effects should be considered in genetic evaluation models in order to obtain accurate prediction of the breeding values of the individuals, assuring more efficient selection. Genetic correlations between direct and maternal additive genetic effects were also important for the traits analyzed, although negative. However, this antagonism between direct and maternal effects could be better investigated accounting for environmental dam-offspring covariances in models and inclusion of the ability to fit the residual variance structure required for maternal effects into existing software packages.

\section{ACKNOWLEDGMENTS}

Research supported by FAPESP (Fundação de Amparo à Pesquisa do Estado de São Paulo) and CNPq (Conselho Nacional de Desenvolvimento Científico e Tecnológico).

\section{REFERENCES}

Aggrey SE and Cheng KM (1993). Genetic and posthatch parental influences in growth of pigeon squabs. J. Hered. 84: 184-187.

Agroceres Ross (2004). Manual de Manejo de Frangos Agross. UmDesign, Campinas.

Aho P (2001). The new poultry elite. WATT Poultry 2: 20-24.

Argentão C, Michelan Filho T, Marques JB, Souza EM, et al. (2002). Genetic and phenotypic parameters of growth and carcass traits of a male line of broilers raised in tropical conditions. Proceedings of the 7th World Congress on Genetics Applied to Livestock Production, 2002, Montpellier, France, 333-336.

Benyshek LL, Johnson MH, Little DE and Kriese LA (1988). Applications of an animal model in the United States beef cattle industry. J. Dairy Sci. 71 (Suppl 2): 35-53.

Bijma P (2006). Estimating maternal genetic effects in livestock. J. Anim. Sci. 84: 800-806.

Boldman KG, Kriese LA, van Vleck LD, van Tassel CP, et al. (1995) A Manual for Use of MTDFREML. A Set of Programs to Obtain Estimates of Variances and Covariances (DRAFT). USDA/ARS, Lincoln.

Chambers JR (1990). Genetics of Growth and Meat Production in Chickens. In: Poultry Breeding and Genetics (Crawford RD, ed.) Elsevier Science, Amsterdam, 599-643.

Chapuis H, Tixier-Boichard M, Delabrosse Y and Ducrocq V (1996). Multivariate restricted maximum likelihood estimation of genetic parameters for production traits in three selected Turkey strains. Genet. Sel. Evol. 28: 299-317.

Clément V, Bibe B, Verrier E, Elsen JM, et al. (2001). Simulation analysis to test the influence of model adequacy and data structure on the estimation of genetic parameters for traits with direct and maternal effects. Genet. Sel. Evol. 33: 369-395.

Dobson AJ (2002). An Introduction to Generalized Linear Models. 2nd edn. Chapman \& Hall/CRC, Boca Raton.

Etches RJ (1995). Reproduction in Poultry. CAB International, Wallingford.

Falconer DS and Mackay TFC (1996). Introduction to Quantitative Genetics. 4th edn. Longman, Essex.

Flemming JS, Janzen AS and Endo MA (1999). Rendimento de carcaça em linhagens comerciais de frangos de corte. Arch. Vet. Sci. 4: 61-63.

Gaya LG, Nakashima SH, Mourão GB, Mattos EC, et al. (2005). Estimativas de Parâmetros Genéticos e Fenotípicos para Medidas de Ultra-Sonografia de Músculo Peitoral e Características de Carcaça em Linhagem Macho de Frangos. In: Anais da $42^{\mathrm{a}}$ Reunião Anual da Sociedade Brasileira de Zootecnia, Goiânia.

Gaya LG, Ferraz JB, Rezende FM, Mourao GB, et al. (2006). Heritability and genetic correlation estimates for performance 
and carcass and body composition traits in a male broiler line. Poult. Sci. 85: 837-843.

Gerstmayr S (1992). Impact of the data structure on the reliability of the estimated genetic parameters in an animal model with maternal effects. J. Anim. Breed. Genet. 109: 321-336.

Harms RH (1991). Specific gravity of eggs and eggshell weight from commercial layers and broiler breeders in relation to time of oviposition. Poult. Sci. 70: 1099-1104.

Henderson CR (1984). Applications of Linear Models in Animal Breeding. University of Guelph, Guelph.

Hohenboken WD (1985). Maternal Effects. In: General and Quantitative Genetics (Chapman AB, ed.). Elsevier, Amsterdam, 135-149.

Koerhuis ANM and McKay JC (1996). Restricted maximum likelihood estimation of genetic parameters for egg production traits in relation to juvenile body weight in broiler chickens. Livest. Prod. Sci. 46: 117-127.

Koerhuis ANM and Thompson R (1997). Models to estimate maternal effects for juvenile body weight in broiler chicken. Genet. Sel. Evol. 29: 225-249.

Koerhuis ANM, McKay JC, Hill WG and Thompson R (1997). A genetic analysis of egg quality traits and their maternal influence on offspring-parental regressions of juvenile body weight performance in broiler chickens. Genet. Sel. Evol. 49: 203-215.

Le Bihan-Duval E, Mignon-Grasteau S, Millet N and Beaumont C (1998). Genetic analysis of a selection experiment on increased body weight and breast muscle weight as well as on limited abdominal fat weight. Br. Poult. Sci. 39: 346-353.

Lesson S and Summers JD (2000). Broiler Breeder Production. University Books, Guelph.

Lynch M and Walsh B (1998). Genetics and Analysis of Quantitative Traits. Sinauer, Sunderland.

Meyer K (1992). Variance components due to direct and maternal effects for growth traits of Australian beef cattle. Livest. Prod. Sci. 31: 179-204.

Meyer K (1997). Estimates of genetic parameters for weaning weight of beef cattle accounting for direct-maternal environmental covariances. Livest. Prod. Sci. 52: 187-199.

Norris D and Ngambi JW (2006). Genetic parameter estimates for body weight in local Venda chickens. Trop. Anim. Health Prod. 38: 605-609.

Pakdel A, Van Arendonk JA, Vereijken AL and Bovenhuis H (2002). Direct and maternal genetic effects for ascitesrelated traits in broilers. Poult. Sci. 81: 1273-1279.

Pita FVC and Albuquerque LG (2001). Comparação de diferentes modelos para avaliação genética de características de desempenho pós-desmama em suínos. Rev. Bras. Zootec. 30: 1720-1727.

Pollock DL (1997). Maximizing yield. Poult. Sci 76: 1131-1133.

Prado-González EA, Ramírez-Avila L and Segura-Correa JC (2003). Genetic parameters for body weights of Creole chickens from Southeastern Mexico using an animal model. Livest. Res. Rural Devel. 15: 1-6. Availabe at [http:// www.lrrd.org/lrrd15/1/prad151.htm].

Reece WO (2006). Dukes: Fisiologia dos Animais Domésticos. 12nd edn. Guanabara Koogan, Rio de Janeiro.

Robinson DL (1996). Models which might explain negative correlations between direct and maternal genetic effects. Lives. Prod. Sci. 45: 111-112.

Saatci M, Omed H and Ap Dewit I (2006). Genetic parameters from univariate and bivariate analyses of egg and weight traits in Japanese quail. Poult. Sci. 85: 185-190.

SAS Institute (2004). User's Guide: Statistics. SAS Institute Inc., Cary.

Willham RL (1980). Problems in estimating maternal effects. Livest. Prod. Sci. 7: 405-418.

Zerehdaran S, Vereijken AL, Van Arendonk JA and van der Waaijt EH (2004). Estimation of genetic parameters for fat deposition and carcass traits in broilers. Poult. Sci. 83: 521-525. 